\title{
Os indígenas Xavante no Censo Demográfico de 2010
}

\author{
Luciene Guimarães de Souza* \\ Silvia Angela Gugelmin* ${ }^{\star *}$ \\ Barbara Coelho Barbosa da Cunha** \\ Marina Atanaka ${ }^{\star \star \star \star}$
}

O objetivo deste artigo é apresentar, a partir de dados do Censo Demográfico de 2010, a distribuição geográfica e algumas características sociodemográficas dos indígenas da etnia Xavante no Brasil. Para tanto, foram utilizadas as seguintes variáveis do questionário básico do Censo: etnia; situação de domicílio; localização do domicílio (dentro ou fora de Terra Indígena - TI); cor ou raça; língua falada no domicílio; renda; e alfabetização. A captação dos dados foi realizada no Banco Multidimensional de Estatística (BME) do Instituto Brasileiro de Geografia e Estatística, considerando as TI Xavante, os 15 municípios onde estão inseridas as TI, os três municípios no entorno dessas TI e o município de Cuiabá. Dos 19.259 declarados indígenas Xavante, 91,6\% residiam em área rural e $85,9 \%$ falavam a língua indígena no domicílio. Os municípios de Campinápolis, Barra do Garças, Nova Nazaré e General Carneiro, juntos, somavam $75,1 \%$ do contingente populacional residente em área rural. Nas TI Areões, Pimentel Barbosa e Sangradouro-Volta Grande, todos se declararam indígenas e da etnia Xavante. Nas TI Chão Preto e Marechal Rondon somente a pergunta "se considera indígena" conseguiu captá-los, pois todos se declararam em outras categorias de cor ou raça. Uma comparação com outra fonte de informações indica que os dados populacionais totais do Censo 2010 são compativeis com aqueles encontrados no registro da área da saúde. Considera-se que, para o caso Xavante, o Censo de 2010 tem um grande potencial para análises de dados demográficos e poderia ser avaliado para outras etnias indígenas específicas, desde que comparados com informações socioantropológicas.

Palavras-chave: Povos indígenas. Demografia. Censo Demográfico. Xavante.

\footnotetext{
*Fundação Oswaldo Cruz (Fiocruz), Escola Nacional de Saúde Pública (Ensp), Rio de Janeiro-RJ, Brasil (Iguimasouza@ gmail.com).

** Instituto de Saúde Coletiva, Universidade Federal de Mato Grosso (UFMT), Cuiabá-MT, Brasil (sigugel@gmail.com).

*** Fundação Oswaldo Cruz (Fiocruz), Escola Nacional de Saúde Pública (Ensp), Rio de Janeiro-RJ (barbaracbc@gmail.com).

**** Instituto de Saúde Coletiva, Universidade Federal de Mato Grosso (UFMT), Cuiabá-MT, Brasil (marina.atanaka@gmail.com).
} 


\section{Introdução}

Um expressivo esforço tem ocorrido no sentido de ampliar a captação de dados acerca das populações indígenas nas estatísticas nos diversos países da América Latina (DEL POPOLO; OYARCE, 2005). Esse esforço associa-se com modificações em cenários políticos que, decorrentes de perspectivas multiculturalistas, têm valorizado a presença indígena nos contextos nacionais, o que fica evidente nas revisões constitucionais ocorridas nas duas últimas décadas em vários países. No caso do Brasil, a Constituição de 1988 trouxe o reconhecimento dos direitos indígenas, instituindo uma nova relação entre o Estado e esses povos.

Fruto dessas mudanças, desde o final dos anos 1990, vêm sendo implementadas políticas públicas direcionadas aos povos indígenas no Brasil, com destaque para as áreas de educação e saúde (BRASIL, 2010, 2011). Nesse processo se insere o esforço de ampliar a coleta de dados sociodemográficos para esse segmento específico da população. Na área da saúde, tem se ampliado a cobertura dos registros para indígenas em sistemas de informação, como o Sistema de Informação de Mortalidade (SIM) e o Sistema de Informação de Nascidos Vivos (Sinasc), ambos de grande importância para compreender as transformações nos perfis demográficos e epidemiológicos dos indígenas (CARDOSO et al., 2005; LIMA et al., 2009; MELLO JORGE et al., 2010).

Além dos sistemas de informação de registros vitais, nota-se também que a ênfase no segmento indígena da população brasileira tem crescido em outras importantes fontes de dados com representatividade nacional. É o caso do Censo Demográfico, que a partir de 1991 passou a incluir no quesito cor ou raça a categoria indígena. Em linhas gerais, a obtenção de dados demográficos sobre os indígenas em 1991 foi conceitualmente semelhante no Censo 2000, enquanto naquele realizado em 2010 foram implementadas importantes modificações nos questionários básico e da amostra, dentre as quais a inclusão de perguntas sobre o pertencimento étnico e línguas faladas no domicílio, para populações residentes em Terras Indígenas, a partir da incorporação de um novo recorte geográfico: a localização do domicílio indígena dentro ou fora de Terras Indígenas demarcadas (IBGE, 2012).

Com a captação de informações sobre etnias indígenas, abre-se a oportunidade para análise dos perfis demográficos que emergem para povos indígenas específicos. A comparação dos dados censitários com outros registros poderá elucidar se este esforço de contagem e caracterização da população e dos domicílios do país reflete as particularidades desta população que, se sabe, é culturalmente diferenciada e está distribuída em espaços geográficos distintos.

Nesse sentido, o presente artigo procura abordar as características sobre a distribuição geográfica dos indígenas Xavante, assim como alguns aspectos sociodemográficos, com base nos dados captados pelo Censo 2010. Adicionalmente, a fim de conhecer as capacidades e limitações na cobertura do Censo Demográfico, realiza-se uma comparação com outra fonte de dados. A escolha desta etnia considerou o fato de, em termos populacionais, 
representar o maior contingente étnico do Estado de Mato Grosso. ${ }^{1}$ Outra particularidade relevante a respeito dos Xavante se insere no contexto da assistência à saúde: dos 34 distritos sanitários especiais indígenas (DSEI), somente quatro são monoétnicos, entre os quais o DSEI Xavante.

\section{População de estudo e localização}

As referências históricas mais antigas sobre os Xavante datam do século XVIII, situando-os nas regiões norte e centro do atual Estado de Goiás, sendo a mobilidade uma característica marcante desse povo, com longos períodos de dispersão no território. Naquela época as bandeiras mineradoras iniciavam sua expansão na Capitania de Goiás, o que levou à política de aldeamentos, redução e pacificação dos índios. Os Xavante tornaram-se alvo de campanhas militares, invasões e escravidão, ataques nos aldeamentos e projetos de reassentamentos, fatos que os motivaram a se deslocar para a região leste, estabelecendo-se no lado oeste do Rio Araguaia. Quanto à população Xavante na época, as referências mencionam entre 2 e 8 mil indivíduos (LAZARIN, 1985; RAVAGNANI, 1991; CHOVELON et al., 1996; COIMBRA JR. et al., 2002).

No século XX, o contato dos grupos Xavante com a sociedade não indígena ocorreu de forma e época diferenciadas. Em 1946, na impossibilidade de outros recuos e com seu território muito reduzido, os grupos que atualmente habitam a região de Pimentel Barbosa e Areões estabeleceram contato permanente com a sociedade envolvente, por meio do Serviço de Proteção ao Índio (SPI). Entretanto, até meados de 1950, alguns grupos permaneceram relativamente isolados e independentes. Essa relativa independência foi logo minada pela ocupação de suas terras por não índios (MAYBURY-LEWIS, 1984; LOPES DA SILVA, 1992; COIMBRA JR. et al., 2002; GARFIELD, 2014).

0 território Xavante localiza-se no Planalto Central brasileiro, entre o Rio das Mortes e os formadores do Rio Xingu, no leste do Estado de Mato Grosso. Como descrito por Ravagnani (1991) e Maybury-Lewis (1984), existem vários grupos Xavante que, embora partilhem de uma única organização social, apresentam históricos de contato e modos distintos de interação entre si e com outros segmentos da população. Não constituem uma unidade política e suas aldeias são autônomas. Essa peculiaridade da sociedade Xavante está refletida na atual situação fundiária e na sua mobilidade.

A autonomia dos Xavante tem sido abordada na literatura etnológica. Por exemplo, Lopes da Silva (1986, p. 35) distribui os Xavante em três grandes grupos conforme a intensidade e característica dos contatos entre aldeias, a continuidade ou não de permanência no território tradicional e os agentes do contato (representantes do Estado ou da Igreja). De acordo com essa sistematização, haveria os seguintes blocos: Pimentel Barbosa e Areões;

\footnotetext{
10 povo Xavante tem sido estudado sob a perspectiva da demografia há mais de 20 anos (FLOWERS, 1994; SOUZA; SANTOS, 2001; PEREIRA, 2011; SOUZA et al., 2011).
} 
Batovi (Marechal Rondon) e Culuene (Parabubure), marginalmente também Couto Magalhães (Parabubure); e Sangradouro-Volta Grande e São Marcos, assim como Couto Magalhães.

O início da definição legal das terras Xavante pela Fundação Nacional do Índio (Funai) ocorreu entre 1970 e 1980, embora permaneçam inúmeras contestações, devido a limites fixados no processo demarcatório não correspondente ao pleiteado, e terras ainda não homologadas. ${ }^{2}$ Assim, este povo, que antes ocupava um território extenso no Estado de Mato Grosso, passou a viver em sete Terras Indígenas (TI) descontínuas - Areões, Marãiwatsede, Marechal Rondon, Parabubure, Pimentel Barbosa, Sangradouro-Volta Grande e São Marcos. As terras Chão Preto e Ubawawe são contíguas às terras já demarcadas, Parabubure e São Marcos, respectivamente (Quadro 1). Cada uma dessas terras tem um histórico de contato diferenciado com a sociedade circundante, mas, no geral, as áreas ao seu redor são ocupadas por não índios (posseiros, latifundiários do agronegócio e empresas agropecuárias, estradas, povoados e missões religiosas). Cabe lembrar que o perímetro territorial das Terras Indígenas Xavante não necessariamente está situado em um único município.

Neste artigo, as Terras Indígenas Xavante investigadas são aquelas que, no Censo de 2010, estavam na situação fundiária considerada declarada, homologada ou regularizada: Pimentel Barbosa; Areões; Chão Preto; Sangradouro-Volta Grande; São Marcos; Parabubure; Ubawawe; Marechal Rondon; e Marãiwatsede. As áreas Eterãirebere, Hu'uhi, Norotsurã e Isoú'pá estavam com o processo de regularização em andamento e para estas terras o IBGE não divulgou informações demográficas (Quadro 1).

QUADRO 1

Caracterização das Terras Indígenas Xavante Estado de Mato Grosso - 2009

\begin{tabular}{|c|c|c|c|c|}
\hline $\begin{array}{l}\text { Nome da Terra } \\
\text { Indígena }\end{array}$ & $\begin{array}{l}\text { Situação } \\
\text { fundiária }\end{array}$ & Área (ha.) & $\begin{array}{c}\text { Ano da } \\
\text { homologação }\end{array}$ & Municípios \\
\hline Areões & Regularizada & 218.515 & 1996 & Água Boa, Nova Nazaré \\
\hline Chão Preto & Regularizada & 12.742 & 2001 & Campinápolis \\
\hline Marãiwatsede & Regularizada & 165.241 & 1998 & $\begin{array}{l}\text { Alto Boa Vista, Bom Jesus do Araguaia, São } \\
\text { Félix do Araguaia }\end{array}$ \\
\hline Marechal Rondon & Regularizada & 98.500 & 1996 & Paranatinga \\
\hline Parabubure & Regularizada & 224.447 & 1991 & Água Boa, Campinápolis, Nova Xavantina \\
\hline Pimentel Barbosa & Regularizada & 328.966 & 1986 & Canarana, Ribeirão Cascalheira \\
\hline $\begin{array}{l}\text { Sangradouro- } \\
\text { Volta Grande }\end{array}$ & Regularizada & 100.280 & 1991 & $\begin{array}{l}\text { General Carneiro, Poxoréo, Novo São } \\
\text { Joaquim }\end{array}$ \\
\hline São Marcos & Regularizada & 188.478 & $1994(1)$ & Barra do Garças \\
\hline Ubawawe & Regularizada & 52.234 & 2000 & Novo São Joaquim \\
\hline Eterãirebere & Em estudo & 0 & - & $\begin{array}{l}\text { Campinápolis, Novo São Joaquim, Santo } \\
\text { Antônio do Leste }\end{array}$ \\
\hline Hu'uhi & Em estudo & 0 & - & Paranatinga \\
\hline Isoú’pà & Em estudo & 0 & - & Água Boa, Campinápolis, Nova Xavantina \\
\hline Norotsurã & Em estudo & 0 & - & Água Boa, Campinápolis, Nova Xavantina \\
\hline
\end{tabular}

Fonte: Fundação Nacional do Índio - Funai, Diretoria de Assuntos Fundiários - DAF, 2009. (1) Data do registro em cartório.

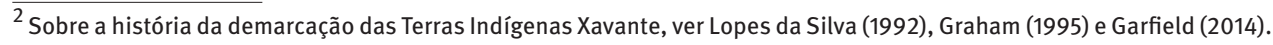




\section{Delineamento do estudo}

Este é um estudo transversal, do tipo descritivo com base de dados secundária. Os dados analisados foram extraídos em 14 de novembro de 2015, dos microdados do Banco Multidimensional de Estatística (BME), referentes ao questionário básico do Censo Demográfico 2010, que possui informações em nível de domicílios e indivíduos.

Para evitar a identificação dos indivíduos e resguardar a confidencialidade dos dados, ao disponibilizar o resultado para cruzamentos de dados do universo, foi estabelecido pelo IBGE que no BME seria colocado um "X" quando a frequência do grupo populacional em determinado cruzamento era inferior a seis observações. Assim, no caso da população indígena, se deparou com um dilema, já que era grande o número de observações com essa marca, visto que a população de algumas etnias é pequena. Para reduzir o número de perdas optou-se por uma aproximação dos valores numéricos, imputando o valor quase central (3) daqueles que eram possíveis de se observar, ignorando que poderia haver zero pessoa no cruzamento.

A fim de identificar a distribuição dos Xavante no território brasileiro, foram realizadas buscas em dois tipos de áreas geográficas: cinco macrorregiões do Brasil; e municípios do Estado de Mato Grosso. Todas as TI Xavante estão situadas no Mato Grosso, mas ressalta-se que esta população não se restringe às Terras Indígenas. Foram selecionados 19 municípios do estado, com o intuito de uma aproximação com as áreas rurais, onde se concentram as Terras Indígenas desta etnia. Os municípios onde estão localizadas as TI são: Água Boa, Alto Boa Vista, Barra do Garças, Bom Jesus do Araguaia, Campinápolis, Canarana, General Carneiro, Nova Nazaré, Nova Xavantina, Novo São Joaquim, Paranatinga, Poxoréo, Ribeirão Cascalheira, Santo Antônio do Leste e São Félix do Araguaia. Adicionalmente foram incluídos três municípios que fazem divisa com municípios de TI Xavante (Chapada dos Guimarães, Pontal do Araguaia e Primavera do Leste) e a capital do estado, Cuiabá.

A população de estudo correspondeu às pessoas que se declararam indígenas no quesito cor ou raça (que tem as categorias branca, preta, parda, amarela e indígena). Destas, foram selecionadas aquelas que afirmaram ser da etnia Xavante no quesito sobre etnia ou povo a que pertence, disponível somente para pessoas que se declaravam indígena. A informação sobre TI foi coletada diretamente pelo IBGE, que, ao ir a campo, já tinha a informação no aplicativo de coleta sobre a "localização do setor do domicílio (se dentro ou fora de Terra Indígena)".

As demais variáveis utilizadas no estudo foram: situação do domicílio (urbano/rural); idade; sexo; língua falada; rendimento total; alfabetização; e se considera indígena (dirigida às pessoas residentes dentro dos limites das Terras Indígenas, mas que no quesito "cor ou raça" não se declararam indígenas).

Para elaboração dos mapas foi utilizada a malha digital dos municípios do Estado de Mato Grosso, disponibilizada pelo IBGE (2015). ${ }^{3}$ Para visualização espacial da população

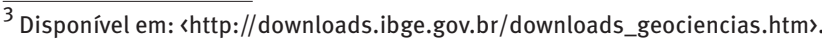


indígena no estado utilizou-se o programa TerraView 4.4.2. ${ }^{4}$ No caso particular dessa distribuição foi considerada a situação do domicílio da população residente no Estado de Mato Grosso por município.

Para a comparação com outras fontes de dados, foram empregados os dados de 2010 do Sistema de Informação da Atenção à Saúde Indígena (Siasi), ${ }^{5}$ para a população Xavante residente nos 34 distritos sanitários especiais indígenas (DSEI) da Secretaria Especial de Saúde Indígena (Sesai). Essa secretaria mantém registros contínuos realizados pelas equipes multidisciplinares atuantes nas aldeias. Os DSEI, criados pela Lei n. 9.836 de 24 de setembro de 1999, são unidades de responsabilidade sanitária federal correspondentes a uma ou mais Terras Indígenas.

\section{Resultados}

\section{Localização da população Xavante}

No Censo 2010 foram coletadas informações de 19.259 indígenas Xavante, sendo que a maioria $(91,6 \%)$ residia em área rural. Embora com maior concentração da população na macrorregião Centro-Oeste (95,7\%), os Xavante foram encontrados em todo o território nacional. Dos indígenas que viviam fora do Centro-Oeste, a Região Sudeste se destaca com maior percentual de Xavante $(61,2 \%)$, sendo que $96,2 \%$ deles viviam na área urbana (Tabela 1).

TABELA 1

Distribuição dos Xavante, por situação de domicílio, segundo macrorregiões Brasil - 2010

\begin{tabular}{|c|c|c|c|c|c|}
\hline \multirow{2}{*}{ Macrorregiões } & \multirow{2}{*}{ Total } & \multicolumn{2}{|c|}{ Urbano } & \multicolumn{2}{|c|}{ Rural } \\
\hline & & $\mathrm{N}$ & $\%$ & $\mathrm{~N}$ & $\%$ \\
\hline Centro-Oeste & 18.437 & 861 & 53,3 & 17.576 & 99,6 \\
\hline Nordeste & 120 & 106 & 6,6 & 14 & 0,07 \\
\hline Norte & 115 & 89 & 5,5 & 26 & 0,15 \\
\hline Sudeste & 503 & 484 & 30,0 & 19 & 0,11 \\
\hline Sul & 84 & 74 & 4,6 & 10 & 0,06 \\
\hline Total & 19.259 & 1.614 & 100,0 & 17.645 & 100,0 \\
\hline Brasil (\%) & 100,0 & & 8,4 & & 91,6 \\
\hline
\end{tabular}

Fonte: IBGE. Censo Demográfico 2010. Dados do universo.

Com relação à unidade da federação, o Censo Demográfico captou os Xavante, em sua vasta maioria, residentes no Estado de Mato Grosso (93,2\%), onde estão situadas as TI dessa etnia. Ressalta-se que os Xavante que vivem fora do Mato Grosso $(6,8 \%)$ moram em Goiás (321), São Paulo (257), Minas Gerais (121), Rio de Janeiro (114) e Distrito Federal (109), que, somados ao Estado de Mato Grosso, reúnem aproximadamente $98 \%$ do contingente populacional Xavante.

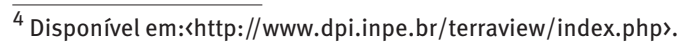

${ }^{5}$ Para saber mais sobre o Siasi, ver Sousa et al. (2007).
} 
Os resultados encontrados no Censo se aproximam daqueles registrados pelo Siasi no mesmo período, inclusive tendo sido captado maior número no primeiro do que no registro. Em 2010 foram registrados 17.905 indivíduos Xavante distribuídos em sete DSEI do país, estando estes majoritariamente (17.887) no DSEI Xavante, localizado no Estado de Mato Grosso. Além destes, o Siasi registrou a presença de Xavante nos DSEI Araguaia (2 indivíduos), Cuiabá (1), ambos no Mato Grosso, Litoral Sul (6), Maranhão (1), Mato Grosso do Sul (7), Minas Gerais e Espírito Santo (1).

Dentro das nove TI Xavante regularizadas, o Censo captou 19.213 pessoas, como pode ser observado na Tabela 2, sendo que $80,4 \%$ declararam-se indígenas, 15,1\% não se declararam, mas se consideravam, 3,8\% não se declararam e não se consideravam e 0,7\% não declararam sua condição indígena. Nas TI Areões, Pimentel Barbosa e Sangradouro-Volta Grande, todos se declararam indígenas e da etnia Xavante. Na TI Marechal Rondon, foram recenseados 549 indivíduos e estes não se declararam indígena no quesito cor ou raça, mas 548 se consideraram indígenas após a pergunta induzida.

Importante ressaltar a situação da TI Marãiwatsede, onde foram identificadas 2.427 pessoas vivendo nessa área, sendo que 1.178 não se declararam, mas se consideraram indígenas. Esta TI está localizada no município de Alto Boa Vista e os indígenas vivem somente na zona rural. Verifica-se também que nos municípios limítrofes, como Bom Jesus do Araguaia e São Félix do Araguaia, constam menos de cinco Xavante por município. Cabe lembrar que as TI Eterãirebere, Hu'uhi, Norotsurã e Isoú'pà não tiveram seus dados divulgados pelo IBGE, sobretudo por se tratar de áreas ainda em estudo pela Funai (Quadro 1).

TABELA 2

Distribuição da população nas Terras Indígenas Xavante, por situação de declaração sobre a categoria indígena - 2010

\begin{tabular}{|c|c|c|c|c|c|c|c|c|c|c|c|}
\hline \multirow[t]{2}{*}{$\begin{array}{c}\text { Terras } \\
\text { Indígenas }\end{array}$} & \multicolumn{2}{|c|}{$\begin{array}{l}\text { Declararam-se } \\
\text { indígenas }\end{array}$} & \multicolumn{2}{|c|}{$\begin{array}{c}\text { Não se } \\
\text { declararam, } \\
\text { mas se } \\
\text { consideravam } \\
\text { indígenas }\end{array}$} & \multicolumn{2}{|c|}{$\begin{array}{c}\text { Não se } \\
\text { declararam } \\
\text { e não se } \\
\text { consideravam } \\
\text { indígenas }\end{array}$} & \multicolumn{2}{|c|}{$\begin{array}{c}\text { Sem } \\
\text { declaração } \\
\text { da condiçãa } \\
\text { indígena }\end{array}$} & \multirow{2}{*}{$\begin{array}{c}\text { Total } \\
\text { linha } \\
\%\end{array}$} & \multicolumn{2}{|c|}{$\begin{array}{l}\text { População } \\
\text { total da TI }\end{array}$} \\
\hline & $\mathrm{N}$ & $\%$ & $\mathrm{~N}$ & $\%$ & $\mathrm{~N}$ & $\%$ & $\mathrm{~N}$ & $\%$ & & $\mathrm{~N}$ & $\%$ \\
\hline Areões & 965 & 100,0 & - & - & - & - & - & - & 100,0 & 965 & 5,0 \\
\hline Marãiwatsede & 767 & 31,6 & 1.178 & 48,5 & 407 & 16,8 & 75 & 3,1 & 100,0 & 2.427 & 12,6 \\
\hline Parabubure & 7.732 & 90,1 & 660 & 7,7 & 152 & 1,8 & 34 & 0,4 & 100,0 & 8.578 & 44,7 \\
\hline $\begin{array}{l}\text { Pimentel } \\
\text { Barbosa }\end{array}$ & 1.740 & 99,8 & $x$ & 0,2 & - & - & - & - & 100,0 & 1.743 & 9,1 \\
\hline $\begin{array}{l}\text { Sangradouro/ } \\
\text { Volta Grande }\end{array}$ & 882 & 100,0 & - & - & - & - & - & - & 100,0 & 882 & 4,6 \\
\hline São Marcos & 3.130 & 99,8 & 8 & 0,3 & - & - & - & - & 100,0 & 3.138 & 16,3 \\
\hline Chão Preto & - & - & 255 & 75,7 & 73 & 21,7 & 9 & 2,7 & 100,0 & 337 & 1,8 \\
\hline $\begin{array}{l}\text { Marechal } \\
\text { Rondon }\end{array}$ & - & - & 548 & 99,8 & - & - & $x$ & 0,2 & 100,0 & 549 & 2,9 \\
\hline Ubawawe & 237 & 39,9 & 254 & 42,8 & 95 & 16,0 & 8 & 1,3 & 100,0 & 594 & 3,1 \\
\hline Total & 15.453 & 80,4 & 2.906 & 15,1 & 727 & 3,8 & 127 & 0,7 & 100,0 & 19.213 & 100,0 \\
\hline
\end{tabular}

Fonte: IBGE, Censo Demográfico de 2010. Dados agregados do universo.

$X$ - Dados restritos para a proteção da confidencialidade. 
Especificamente no Estado de Mato Grosso, o Censo 2010 identificou 17.925 indivíduos pertencentes à etnia Xavante, dos quais 98,1\% viviam em domicílios em área rural. Do total de 141 municípios do Estado, 24 registraram presença de Xavante somente na área urbana, sendo 21 deles com menos de cinco indivíduos. Já nos municípios de General Carneiro e Alto Boa Vista todos indígenas residiam na zona rural, correspondendo a $10,4 \%$ do total. Destaca-se também a presença maior de moradores na zona urbana do que na rural no município de Cuiabá.

Para compreender a distribuição geográfica dos Xavante residentes em Mato Grosso, foi produzido um mapa em nível municipal (Figura 1) que mostra a concentração desses indígenas em alguns municípios, especialmente nas áreas ao nordeste e sudeste do Estado, destacando-se quatro municípios (Nova Nazaré, Barra do Garças, Campinápolis e General Carneiro) com população Xavante acima de 1.000 habitantes. Em Campinápolis, Nova Nazaré e General Carneiro, os Xavante respondem, respectivamente, por 52,9\%, 38,6\% e $22,1 \%$ da população total do município.

FIGURA 1

Número de habitantes da população Xavante Municípios do Estado de Mato Grosso - 2010

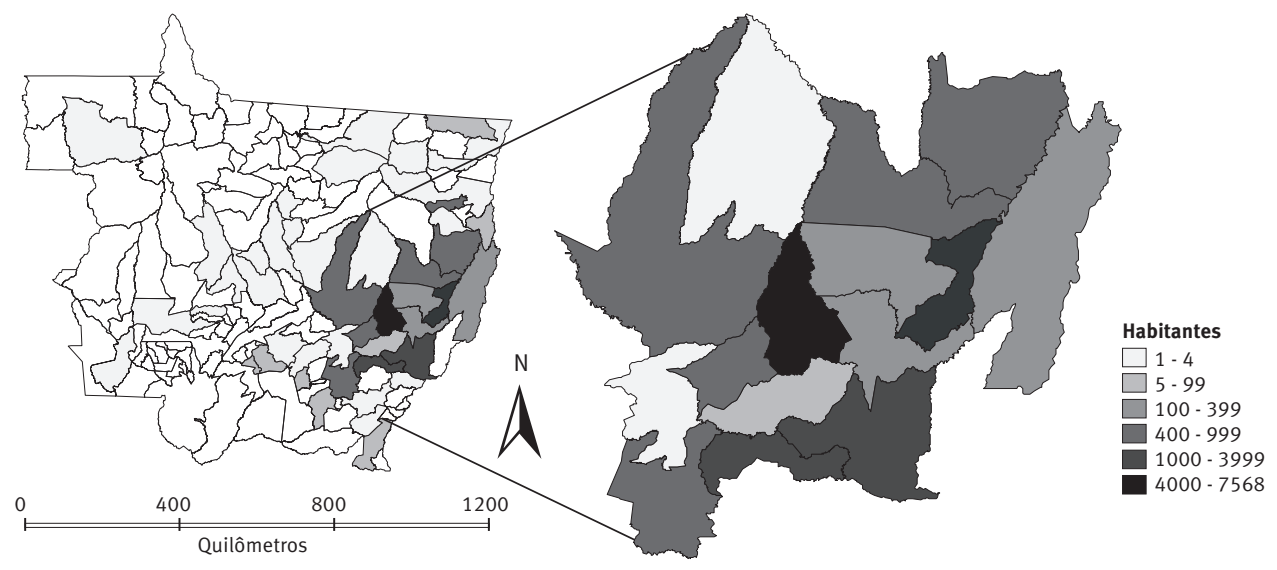

Fonte: IBGE, Censo Demográfico 2010. Dados agregados do universo.

Dos 15 municípios selecionados com TI Xavante, Campinápolis, Barra do Garças, Nova Nazaré e General Carneiro somavam 75,1\% do montante populacional Xavante residente em área rural. Já a maior concentração desses indígenas vivendo em área urbana foi encontrada em Nova Xavantina (42,0\%). Chama a atenção o fato de que neste município não foi captado nenhum residente na área rural.

\section{Características sociodemográficas}

Em relação à distribuição etária, observaram-se variações importantes para o total dos Xavante, segundo situação de domicílio e localidade (dentro ou fora de MT). A população 
urbana, tanto dentro como fora de Mato Grosso, tem traços característicos de uma população com maior número de adultos, diferentemente dos habitantes da área rural, onde a proporção de crianças e adolescentes é quase duas vezes maior do que na área urbana.

Para o Brasil urbano (incluído Mato Grosso), 17,8\% dos Xavante possuíam menos de 15 anos em 2010 e 4,6\% tinham menos de 4 anos, enquanto na área rural tais proporções correspondiam a $52,7 \%$ e $21,6 \%$, respectivamente. Este fato aponta para a ocorrência de maiores taxas de fecundidade nas áreas rurais e também poderia indicar alguma migração de população adulta para as áreas urbanas.

A distribuição da população Xavante residente no Brasil, fora do Estado de Mato Grosso, segundo a situação de domicílio, apresenta uma estrutura etária por sexo caracterizada por disparidades na proporção entre os grupos etários, sobretudo entre os jovens e adultos, devido ao pequeno número da população. De toda forma, percebe-se que a proporção de idosos tem pouca diferença entre urbanos e rurais, verificando-se um menor percentual de idosos no rural (Gráfico 1).

\section{GRÁFICO 1}

Composição relativa da população Xavante, por sexo, segundo grupos etários, segundo situação de domicílio Brasil e Estado de Mato Grosso - 2010

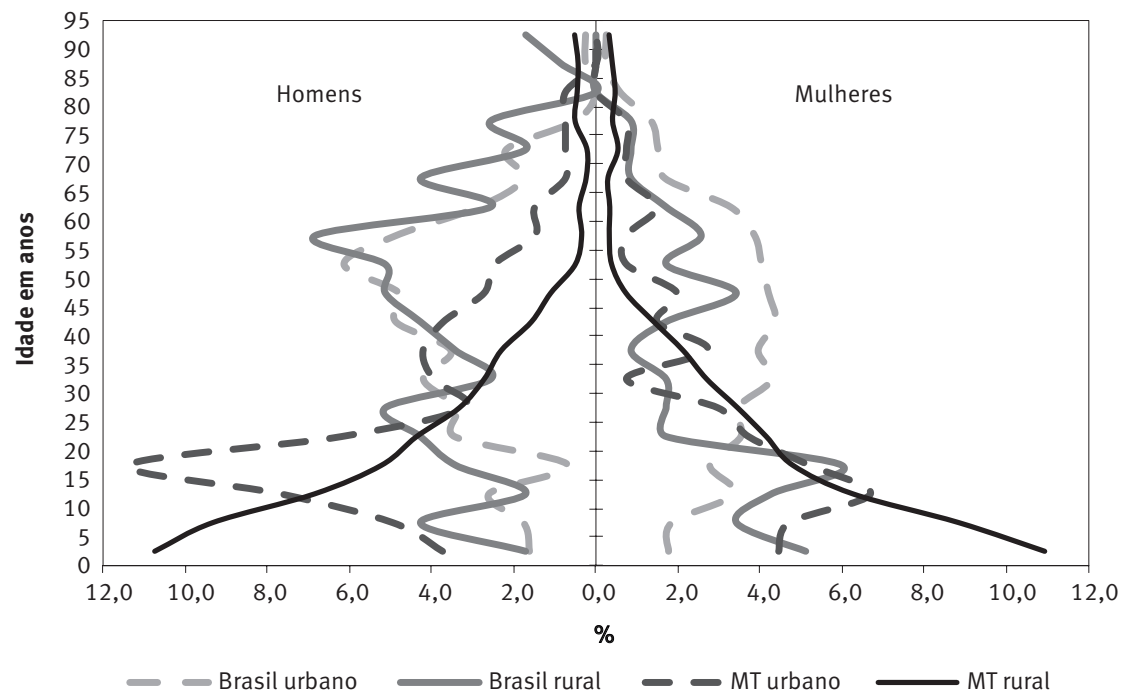

Fonte: IBGE, Censo Demográfico 2010. Dados agregados do universo.

No caso específico do Estado de Mato Grosso, a estrutura etária dos residentes em domicílio na área rural foi predominantemente jovem, com distribuição percentual semelhante entre os sexos. Para os residentes na área urbana, a pirâmide populacional apresentou o mesmo padrão daquela não indígena, com maior proporção de homens em idade produtiva (Gráfico 1). Ainda em relação a Mato Grosso, a base mais estreita da população urbana reflete uma diminuição da natalidade em relação à área rural. Na área urbana, chamam a atenção a concentração de jovens com idade entre 10 e 24 anos e o fato de a população 
masculina de 15 a 24 anos ser o dobro da feminina na mesma faixa etária, comportamento distinto daquele descrito para a área rural.

Outras características investigadas foram língua falada, alfabetização e renda. No geral, a análise da língua falada no domicílio mostra que aproximadamente $86 \%$ do total dos Xavante acima de cinco anos de idade falavam língua indígena (Gráfico 2). Ao se considerar a situação de moradia, 98,1\% dos que falavam língua indígena residiam em área rural e, entre aqueles não falantes da língua, 52,5\% estavam em área rural e 47,5\% em área urbana.

Quanto aos Xavante residentes fora de Mato Grosso, observa-se que, com exceção das faixas etárias de 5 a 9 e 15 a 29 anos em área rural, as frequências dos que falavam língua indígena no domicílio são reduzidas, ficando abaixo de $20 \%$ para todas as faixas etárias. Para o estrato urbano fora de Mato Grosso, há uma notável homogeneidade, no sentido de que menos de $10 \%$, independentemente da faixa etária, reportaram falar língua indígena no domicílio (Gráfico 2).

O Gráfico 2 ainda mostra que, independentemente da faixa etária, mais de $90 \%$ dos Xavante em área rural de Mato Grosso - o que em larga medida coincide com os residentes em Terras Indígenas - reportaram falar língua indígena em seus domicílios. Já entre os residentes em área urbana nesse Estado, aqueles nascidos entre 1941 e 1980 foram os que menos reportaram falar língua indígena no domicílio. Chama a atenção que, em área urbana, mais da metade daqueles de 70 anos ou mais $(57,1 \%)$ indicaram falar língua indígena no domicílio.

GRÁFICO 2

Porcentagem da população Xavante que fala língua indígena no domicilio, por situação de domicílio, segundo faixa etária Brasil e Estado do Mato Grosso - 2010

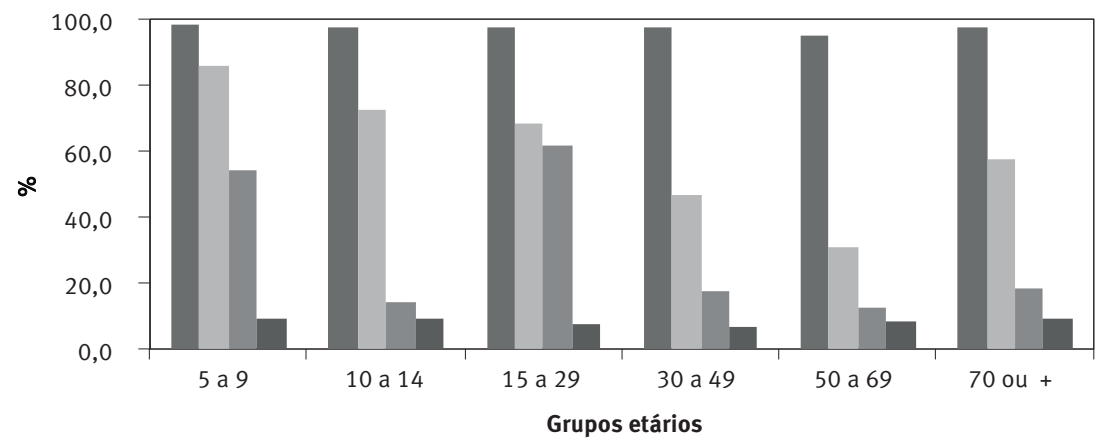

MT-rural MT-urbano Brasil (exceto MT) - rural

Brasil (exceto MT) - urbano

Fonte: IBGE, Censo Demográfico 2010. Dados agregados do universo.

Em relação à alfabetização, 61,9\% dos Xavante sabiam ler e escrever, sendo que há uma diferença substancial entre os sexos, a partir da faixa etária de 15 a 29 anos, para aqueles residentes na área rural de Mato Grosso, cujas maiores frequências de alfabetizados estavam entre os homens. Uma vez que os números absolutos são muito reduzidos para aqueles que viviam na área rural de outros estados, a maior parte dos não alfabetizados 
era moradora do Mato Grosso. Ainda em relação à situação de domicílio, para os residentes fora de Mato Grosso optou-se por analisar o conjunto de indivíduos, sem categorizar por sexo. 0 resultado mostrou que aproximadamente $75,7 \%$ dos Xavante que residiam na área urbana em outras UF sabiam ler e escrever.

Outra variável investigada refere-se à renda mensal total do domicílio, categorizada por salário mínimo (SM). No Brasil, 91,6\% dos Xavante, em 2010, recebiam até um salário mínimo ou não possuíam rendimento. Os Xavante residentes fora do Mato Grosso apresentaram renda mais alta do que aqueles vivendo no Estado, pois entre os moradores do Mato Grosso 80,3\% dos Xavante de dez anos ou mais de idade não possuíam nenhum rendimento, sendo a maior proporção para os residentes na área rural.

\section{Discussão}

A necessidade de incrementar os estudos a respeito das características e da dinâmica demográfica da população indígena brasileira vicejou nos anos 1980. Na ocasião, já se chamava a atenção para a precariedade das escassas informações estatísticas necessárias à compreensão dos principais aspectos das condições de vida dessa população, sua distribuição territorial, estrutura e dinâmica demográficas (PAGLIARO et al., 2005; AZEVEDO, 2011).

A incorporação do quesito indígena na categoria cor ou raça, no questionário da amostra dos Censos Demográficos de 1991 e 2000, foi um avanço para a demografia indígena, que até aquele momento dependia de iniciativas e estudos pontuais com contagem populacional. Esses censos possibilitaram não somente o conhecimento da estrutura e dinâmica demográficas daqueles que se declararam indígenas, mas também questionamentos sobre o expressivo aumento no número desses autodeclarados quando comparados os resultados nas duas décadas (PAGLIARO; AZEVEDO; SANTOS, 2005; PEREIRA; SANTOS; AZEVEDO, 2005).

A ampla discussão dos resultados do Censo 2000 e a formação de comitês e grupos de trabalhos sobre demografia indígena no âmbito da Associação Brasileira de Estudos Populacionais (Abep) e Associação Brasileira de Pós-Graduação em Saúde Coletiva (Abrasco) podem ter contribuído para a inclusão de questões sobre o pertencimento étnico, o considerar-se indígena, a língua falada no domicílio e a localização geográfica para o universo do Censo 2010, aprimorando assim a investigação de segmentos específicos da população brasileira, como os indígenas (IBGE, 2012). Ao mesmo tempo, o Brasil inclui-se entre os países que investigam o pertencimento étnico, recorte que há muitos anos tem sido investigado em diversos países latino-americanos, norte-americanos e da Oceania, fato que explicitou a diversidade étnica existente nesses países e, não raro, a situação de desigualdade dos indicadores indígenas (DEL POPOLO; OYARCE, 2005; STEPHENS et al., 2006).

Neste artigo, optou-se por discutir os dados do Censo 2010 em uma perspectiva micro, ou seja, utilizando os dados captados de uma etnia, no caso os Xavante, para identificar a possibilidade de análises mais específicas sobre os aspectos demográficos 
e territoriais, juntamente aos dados históricos e culturais já publicados na literatura etnológica (GIACCARIA; HEIDE, 1984; FLOWERS, 1994; MAYBURY-LEWIS, 1984; RAVAGNANI, 1991; LOPES DA SILVA, 1984, 1986).

A princípio os resultados do Censo 2010 para os Xavante convergem com a literatura demográfica existente sobre esta população. Entretanto, a captação de informação do Censo extrapola os limites geográficos das Terras Indígenas e agregam mais informações na distribuição dos Xavante por situação de domicílio, especialmente na área urbana, elemento ainda pouco conhecido e explorado pelos pesquisadores e serviços de saúde.

Os resultados mostram que, embora com distintos quantitativos, foram encontrados Xavante em todo o território nacional, com maior concentração da população na macrorregião Centro-Oeste (95,8\%). Além disso, percebe-se que no Estado de Mato Grosso os Xavante estão agrupados especialmente em área rural (98\%). Entre os Xavante que viviam fora do Centro-Oeste, destacam-se alguns achados: maior proporção no Sudeste (2,6\%); residência essencialmente em área urbana; e renda média total mais alta do que a daqueles residentes em áreas urbanas do Mato Grosso.

Para entender o aglomerado dos Xavante em um espaço delimitado, voltou-se aos dados históricos e culturais desse povo. É evidente que, ao delimitar um espaço geográfico (Terra Indígena), o território ocupado por determinado grupo fica restrito. No entanto, isso não define a dispersão dos indivíduos pelo país, vide o exemplo dos Guarani (PISSOLATO, 2004). No caso Xavante, os dados do Censo 2010 demonstram a disposição de permanência no território historicamente ocupado, entre os Rios Araguaia e das Mortes (GIACCARIA; HEIDE, 1984; FLOWERS, 1994; MAYBURY-LEWIS, 1984; RAVAGNANI, 1991). Mas também verifica-se a dispersão Xavante por todo o Brasil, com cerca de 1.334 pessoas em estados próximos a Mato Grosso (Goiás e Distrito Federal) e estados nos quais determinados grupos Xavante mantêm ativada, ao que parece, sua mobilidade, constituindo uma rede de relações com famílias de não indígenas, universidades, instituições de pesquisa governamentais e não governamentais (São Paulo e Rio de Janeiro), conforme observações realizadas no decorrer de 20 anos de trabalhos feitos com os Xavante.

Essa dispersão também parece expressar a mobilidade numa perspectiva de território contínuo, sinais de um processo de reocupação de um território original que thes foi usurpado na época do contato (LOPES DA SILVA, 1992; GARFIELD, 2011, 2014), ou um processo migratório em etapas para distâncias mais curtas em seu início, com posterior ampliação, como comumente visto nos estudos migratórios. Não se dispõe de elementos para discutir diretamente tais argumentos, pois, para tanto, seria necessária uma abordagem histórica da mobilidade e ocupação espacial Xavante, nos moldes do que vem sendo feito para os Guarani, ${ }^{6}$ muito além dos resultados produzidos pelo Censo.

\footnotetext{
${ }^{6}$ Garlet (1997, p. 22) analisa os deslocamentos dos Guarani Mbya no Estado do Rio Grande do Sul como ampliação e ocupação de um território original, um processo de "reterritorialização". 0 autor também trabalha a ideia de um espaço aberto que pode ser ampliado continuadamente.
} 
Um aspecto que repercute na mobilidade Xavante é o casamento. Ainda que a maioria das pessoas se case com membros de sua própria aldeia, a união pode ser entre indivíduos de distintas aldeias e Terras Indígenas, ficando as famílias ligadas por alianças de matrimônio, o que mantém um constante fluxo de visitas a diversas localidades. 0 período de permanência dessas visitas pode durar de semanas a anos, o que dificulta a classificação entre morador ou visitante de passagem (LOPES DA SILVA, 1986) se não forem definidos os conceitos específicos nas pesquisas, que nem sempre refletem toda a complexidade do tema, mas permitem calcular algumas medidas. No caso do Censo Demográfico e outras pesquisas domiciliares, o IBGE assume que a população residente é aquela definida como de direito, ou seja, quem reside no domicílio (ou oca no caso dos indígenas) e não esteve ausente por mais de 12 meses por qualquer motivo que não signifique mudança mais permanente, conforme definição de morador do domicílio/oca (IBGE, 2013). No entanto, o estudo migratório de etnias indígenas não poderia ser realizado com os dados do Censo disponíveis ao uso público, visto que a informação de etnia se encontra somente nos dados do universo e aquela referente à migração interna somente na amostra.

A permanência no território original aparentemente deriva de uma característica da organização social dos indígenas, entre eles os Xavante, relacionada à coesão social. Os laços de parentesco, as relações entre diferentes aldeias e a manutenção das regras de matrimônio entre membros da mesma etnia criam uma base para alianças políticas entre grupos, bem como uma rede social para o indivíduo, o que o liga a uma determinada comunidade (LOPES DA SILVA, 1986). Mesmo estando distante, ele permanece com forte vínculo com a aldeia e o grupo de idade definido durante os rituais de iniciação, gerando um sentimento de pertencimento.

Nesse sentido, cabe refletir sobre a importância de manter a concentração do número de pessoas em um mesmo território a fim de sustentar os rituais que as definem como povo indígena Xavante. Para a realização do ritual de iniciação (Wapté Mnhõnõ) dos meninos, por exemplo, é necessário agregar a população de diversas aldeias, quando estas são muito pequenas. Somente assim as festas ocorrem. Esta festa é importante para os Xavante, pois a partir dela são construídos os laços de pertencimento à classe de idade específica, a qual permanecerá ao longo de sua vida como elemento de diferenciação, e o fortalecimento das alianças políticas (WELCH, 2014).

O pertencimento a um grupo étnico também pode ser definido por meio da língua falada (LOPES DA SILVA, 1984; GRAHAM, 2014), que reflete as representações e construções de uma sociedade, seus valores e concepções de mundo, o modo pelo qual a sociedade se expressa (SIGNORINI, 2002). No caso Xavante, a situação de domicílio (rural ou urbano) e morar fora ou dentro do Estado de Mato Grosso parece ser um fator determinante na conservação da língua indígena como língua falada no domicílio. Particularmente, morar na área urbana fora de Mato Grosso demonstra a baixa vitalidade da língua nesse contexto. Resulta desse fato que a urbanidade pode ser considerada fator de deslocamento da língua indígena para os Xavante. Segundo a Unesco (2009, p. 14), “o prestígio da língua 
dominante e o seu predomínio na vida pública podem levar uma comunidade a desvalorizar a sua própria língua. Assim, a revitalização das línguas depende, antes de qualquer coisa, da reafirmação da identidade cultural, por parte de uma comunidade".

Outro aspecto a se considerar é a possibilidade do fenômeno da multilocalidade advinda da contagem dupla de um indivíduo, seja na aldeia pelos seus parentes, seja na cidade onde reside. Este problema não parece ter ocorrido nos dados coletados no Censo 2010, pois os resultados para os Xavante que vivem no Estado de Mato Grosso são semeIhantes àqueles registrados pelo Siasi no mesmo período e local, ainda que devam ser consideradas as diferentes metodologias, provavelmente devido à correta identificação de população de direito utilizada no Censo.

O Censo Demográfico de 2010 registrou, na data de referência de 31 de julho de 2010, a existência de 17.925 Xavante no Mato Grosso. Por sua vez, os dados do Siasi, para a mesma data, indicam que havia, no DSEI Xavante, 17.887 indígenas. A diferença de 38 pessoas pode estar relacionada à abrangência territorial de captação do Censo. Possivelmente a captação destes indivíduos se deu em outros três distritos sanitários existentes no Estado, dada a distribuição esparsa de alguns. Contudo, os dados produzidos pelo Siasi somente permitem comparar volume de população e estrutura etária.

O Censo Demográfico de 2010 trabalha com as Terras Indígenas como definidas pela Fundação Nacional do Índio, as quais, por sua vez, abarcam vários municípios. Já a população coberta pelo Siasi atém-se, principalmente, àquele contingente que habita territórios distritais. Ou seja, os dados do Siasi referem-se aos DSEI e aos Polos Base, cujas áreas de atuação nem sempre coincidem com as Terras Indígenas ou com um conjunto delas (SOUZA; SANTOS, 2009).

Ressalvas à parte, as similaridades nos totais populacionais podem ser indicadores valiosos da completude conseguida pelas duas abordagens metodológicas. 0 fato de 0 Censo estar captando de forma adequada, pelo menos os Xavante, já foi reportado por Pereira et al. (2009) em estudo comparativo entre os dados coletados pelo Censo 2000 nas Terras Indígenas Xavante e informações populacionais dos estudos de Souza (2008) e Souza et al. (2011).

Pereira et al. (2009) verificaram que, em termos do tamanho da população, distribuição populacional entre as Terras Indígenas e composição etária e por sexo, os resultados do Censo estavam muito próximos aos registros do serviço de atenção à saúde indígena, considerando que o Censo 2000 conseguiu capturar as características básicas da população Xavante. No entanto, para os autores, os instrumentos de coleta censitária não conseguiram captar elementos específicos da organização social dos Xavante dentro dos domicílios, que envolviam regras de moradia e conceito particular de família. Baseados nesses resultados, os autores concluíram que os Censos tinham limitações importantes ao utilizar instrumentos de coleta não adaptados para locais culturalmente distintos.

Por conta das particularidades inerentes aos indígenas, o Censo Demográfico não deve ser a única fonte para análise da situação dessa população. Outras fontes, tais como 
pesquisas conduzidas por organizações governamentais, a exemplo da Fundação Nacional do Índio (Funai), e outras agências não governamentais de apoio à causa indígena, como os censos participativos que foram realizados entre os Sateré Mawé (TEIXEIRA, 2005) e os povos indígenas do Alto Rio Negro (AZEVEDO, 1994), são importantes para se entender o processo de expansão e ocupação de determinado território, entre outros aspectos.

Para o Censo Demográfico de 2010, a inclusão das variáveis "etnia ou povo a que pertence”, "língua falada” e "se considera indígena” no questionário básico (universo) trouxe a possibilidade de analisar a realidade demográfica indígena do país mais detalhadamente. Um dos achados mais significativos do presente estudo refere-se à interpretação da variável "cor ou raça” e à capacidade da variável "se considera indígena" em captar potenciais perdas ou aumento considerável de indígenas nas TI.

As análises realizadas evidenciaram que a pergunta "você se considera" foi fundamental para identificar parte importante dos indígenas Xavante na TI Marechal Rondon (território de ocupação histórica) e Chão Preto, pois nem todos se declararam como indígenas no quesito "cor ou raça". Mas com a segunda pergunta houve um aumento da ordem de $15 \%$ do contingente de pessoas que viviam dentro dessas TI. Nesse caso, o resultado para "você se considera" aponta, no mínimo, para duas possibilidades no momento da coleta: o não entendimento da pergunta sobre "cor ou raça” em função de barreiras linguísticas, ou em decorrência da abordagem do entrevistador.

Por outro lado, os dados também retrataram situações específicas dos Xavante, como deslocamentos de contingente populacional para área urbana devido a conflitos relacionados à terra e à presença de população não indígena em TI. O fato de o município de Nova Xavantina não apresentar indígenas em área rural, somente urbana, constitui exemplo da saída de um montante expressivo de pessoas da TI Parabubure (142 pessoas) que migraram para a cidade devido a conflitos desencadeados por não indígenas. ${ }^{7}$ No entanto, a pergunta "você se considera" identificou um expressivo número de pessoas que se consideravam “indígenas" dentro da TI, sem saber nomear, contudo, a etnia.

A TI Marãiwatsede foi retratada em suas particularidades no que se refere à presença de indígenas e não indígenas residentes. Ressalta-se que a ação judicial para a desintrusão estava em curso na época do Censo 2010 (MATO GROSSO, 2014), o que pode ter influenciado o montante de não declarados indígenas, mas que se consideravam dessa cor ou raça (1.178 pessoas). ${ }^{8}$ Cabe esclarecer que esta TI é uma região recentemente reocupada pelos Xavante após o seu afastamento involuntário em agosto de 1966, cuja população é oriunda, em sua grande maioria, da extinta aldeia Água Branca pertencente à TI de Pimentel Barbosa. Isto posto, a população captada pelo Censo que se declarou indígena e da etnia Xavante que vivia nesta TI era de 767 habitantes em 2010.

\footnotetext{
${ }^{7} 0$ confronto entre madeireiros e Xavante provocou a morte de dois não índios. Temendo represálias e se sentindo vulneráveis pelo isolamento de suas aldeias, os Xavante buscaram refúgio na cidade (SOUZA, 2008).

${ }^{8} \mathrm{Na}$ análise dos indivíduos que não se declararam, mas se consideravam indígenas foram identificadas somente três pessoas que responderam à qual etnia pertencia (Guarani Kaiowa, Bororo e Xavante), o restante não sabia informar (ignorado).
} 
O caso Xavante é ilustrativo e relevante na interpretação dos dados à luz da demografia antropológica. Houve convergência dos dados do Censo 2010 com a literatura no que se refere a volume, distribuição geográfica e estrutura etária da população. Porém, o Censo não é construído para captar as particularidades sociodemográficas e, por isso, é necessário cuidado especial na análise de perguntas específicas como "você se considera”, pois houve evidências de que pessoas se consideraram indígenas sem, de fato, conhecerem sua etnia, especificamente em território indígena em conflito fundiário com posseiros não indígenas.

No entanto, a captação da população indígena somente pelo quesito cor ou raça pode acarretar subenumeração. Isso quase ocorreu em duas terras reconhecidamente Xavante: Chão Preto e Marechal Rondon. Se não houvesse a pergunta de controle da resposta - "você se considera" - dentro das terras indígenas, os residentes nestas duas localidades não teriam sido captados como indígena da etnia Xavante. Estas duas situações demonstram o cuidado necessário na análise deste dado. Para fins descritivos de uma realidade, os dados parecem ser apropriados, mas é imprescindivel conhecer aspectos históricos, políticos e sociais dos povos indígenas em análise a fim de se evitar levantar hipóteses sobre possível super ou subestimação com a pergunta "você se considera indígena".

Os resultados deste artigo sugerem que a metodologia e os instrumentos de captação do Censo podem influenciar na produção de dados. Tal argumento é, em parte, compartilhado por Campos et al. (2006) que, analisando o caso dos Xacriabá a partir do Censo 2000, ressaltam que mesmo fontes confiáveis, como os Censos Demográficos, apresentam problemas com a identificação das populações indígenas, devido às questões sobre identidade e pertencimento.

Nesse sentido, segundo Cavenaghi e Alves (2011), o manual do Censo 2010 não explicita como selecionar o residente do domicílio que irá responder ao questionário, somente que deve ser o responsável pelo domicílio, ou, na sua falta, qualquer pessoa que tenha conhecimento suficiente sobre os outros moradores. No entanto, segundo os autores, observações de campo e análises de relatórios dos recenseadores mostram que estas premissas não são necessariamente seguidas de forma regular e podem desencadear super ou subestimação. Santos et al. (2015), ao investigarem a parturição a partir do Censo de 2010 em indígenas e não indígenas do Norte e Nordeste do Brasil, encontraram que, quando não é a própria mulher que responde ao questionário, os valores de parturição são inferiores.

Entretanto, mesmo com limites, a viabilidade de análise dos resultados dos Censos agrega considerável valor aos estudos demográficos de populações indígenas. E é inegável que o Censo 2010 expandiu esta possibilidade. No entanto, deve-se sempre buscar o aprimoramento da captação dos dados, como, por exemplo, para estimar a cobertura da população recenseada necessita-se de pesquisas de avaliação pós-censitária, realizadas em conjunto com o levantamento do Censo, visto que os dados de registros têm diferentes abordagens metodológicas. Ainda, para amplificar as análises e conhecer melhor sobre a diversidade da população indígena, um passo importante é analisar os dados oriundos de outras fontes e sob a ótica de estudos etnográficos, históricos e sociodemográficos. 


\section{Referências}

AZEVEDO, M. M. O Censo 2010 e os povos indígenas. In: RICARDO, C. A.; RICARDO, F. (Org.). Povos indígenas no Brasil 2006-2010. São Paulo: Instituto Socioambiental, 2011. p. 45-48.

AZEVEDO, M. M. Demografia dos povos indígenas do Alto Rio Negro. Revista Brasileira de Estudos de População, v. 11, n. 2, p. 235-244, 1994.

BRASIL. Ministério da Educação, Secretaria de Educação Continuada, Alfabetização e Diversidade - Secad. Educação escolar indígena: diversidade sociocultural indígena ressignificando a escola. Brasília: MEC, Secad, 2011.

- Ministério da Saúde. Saúde Brasil 2009: uma análise da situação de saúde e da agenda nacional e internacional de prioridades em saúde. Brasília: Ministério da Saúde, Secretaria de Vigilância em Saúde, Departamento de Análise e Situação em Saúde, 2010.

CAMPOS, M. B.; CAMPOS, T. B.; MONTE-MÓR, R. L. M. A questão demográfica indígena: o caso dos Xacriabá, no Norte de Minas Gerais. In: XV ENCONTRO NACIONAL DE ESTUDOS DE POPULAÇÃO. Anais... Caxambu: Abep, setembro de 2006.

CARDOSO, A. M.; SANTOS, R. V.; COIMBRA JR., C. E. A. Mortalidade infantil segundo raça/cor no Brasil: o que dizem os sistemas nacionais de informação? Cadernos de Saúde Pública, Rio de Janeiro, v. 21, n. 5, p. 1602-1608, set./out. 2005.

CAVENAGHI, S.; ALVES, J. Domicilios y familias en la experiencia censal del Brasil: cambios y propuesta para identificar arreglos familiares. Notas de Población, Santiago de Chile, v. 92, p. 15-46, 2011. Disponivel em: 〈http://repositorio.cepal.org/handle/11362/12879〉.

CHOVELON, H.; FERNANDES, F.; SBARDELLOTTO, P. Do primeiro encontro com os Xavante à demarcação de suas reservas. Campo Grande: Missão Salesiana, 1996.

COIMBRA JR., C. E. A.; FLOWERS, N. M.; SALZANO, F. M.; SANTOS, R. V. The Xavante in transition: health, ecology, and bioanthropology in Central Brasil. Ann Arbor: University of Michigan Press, 2002.

COIMBRA JR., C. E. A.; WELCH, J. R. Os Xavante e seus etnógrafos. In: COIMBRA JR., C. E. A.; WELCH, J. (Org.). Antropologia e história Xavante em perspectiva. Rio de Janeiro: Museu do Índio, Fundação Nacional do Índio, 2014. p.1-15.

DEL POPOLO, F.; OYARCE, A. M. América Latina, población indígena: perfil sociodemográfico en el marco de la Conferencia Internacional sobre la Población y el desarrollo y de las metas del milênio. Notas de Población, Santiago de Chile, v. 31, n. 79, 2005. Disponível em: 〈http:// repositorio.cepal.org/bitstream/handle/11362/37704/NP05079_es.pdf?sequence=1〉.

FLOWERS, N. M. Crise e recuperação demográfica: os Xavante de Pimentel Barbosa, Mato Grosso. In: SANTOS, R. V.; COIMBRA JR., C. E. A. (Org.). A saúde e povos indígenas. Rio de Janeiro: Editora Fiocruz, 1994. p. 213-242.

FUNAI. Listagem de Terras Indígenas, 2009. Disponível em: 〈http://www.mpf.mp.br/atuacaotematica/ccr6/documentos-e-publicacoes/docs/terras-indigenas/tis/ListaTerralndigenasFUNAl. xls/view>. Acesso em: 08 fev. 2015.

GARFIELD, S. A luta indígena no coração do Brasil. São Paulo: Unesp, 2011.

Onde a terra toca o céu: a luta dos índios Xavante por terra, 1951-1979. In: COIMBRA JR., C. E. A.; WELCH, J. (Org.). Antropologia e história Xavante em perspectiva. Rio de Janeiro: Museu do Índio, Fundação Nacional do Índio, 2014. p. 39-66.

GARLET, I. J. Mobilidade Mbya: história e significação. 1997. Dissertação (Mestrado) - Pontifícia Universidade Católica do Rio Grande do Sul, Porto Alegre, 1997. 
GIACCARIA, B.; HEIDE, A. Auwê Uptabi, povo autêntico. São Paulo: Editora Salesiana Dom Bosco, 1984 [1972].

GRAHAM, L. R. Performing dreams: discourses of immortality among the Xavante of Central Brazil. Austin: University of Texas Press, 1995.

Uma esfera pública na Amazônia? A construção de discurso colaborativo despersonalizado entre os Xavante. In: COIMBRA JR., C. E. A.; WELCH, J. (Org.). Antropologia e história Xavante em perspectiva. Rio de Janeiro: Museu do Índio, Fundação Nacional do Índio, 2014. p. 123-155.

IBGE - Instituto Brasileiro de Geografia e Estatística. Metodologia do Censo Demográfico 2010. Rio de Janeiro: IBGE, 2013 (Série Relatórios Metodológicos, v. 41). Disponível em: 〈http:// biblioteca.ibge.gov.br/visualizacao/livros/liv81634.pdf〉.

Censo Demográfico 2010: características gerais dos indígenas resultados do universo. Rio de Janeiro: IBGE, 2012.

Tendências demográficas: uma análise dos indígenas com base nos resultados da amostra dos censos demográficos 1991 e 2000. Rio de Janeiro: IBGE, 2005.

LAZARIN, R. H. A. 0 aldeamento Carretão: duas histórias. 1985. Dissertação (Mestrado) Universidade de Brasília - UnB, Brasília, 1985.

LIMA, C. R. A.; SCHRAMM, J. M. A.; COELI, C. M.; SILVA, M. E. M. Revisão das dimensões da qualidade dos dados e métodos aplicados na avaliação dos sistemas de informação em saúde. Cadernos de Saúde Pública, Rio de Janeiro, v. 25, n. 10, p. 2095-2109, out. 2009.

LOPES DA SILVA, A. A expressão mítica da vivência: tempo e espaço na construção da identidade Xavante. Anuário Antropológico, Rio de Janeiro: Tempo Brasileiro; Fortaleza: UFCE, n. 82, p. 200-14, 1984.

Nomes e amigos: da prática Xavante a uma reflexão sobre os Jê. São Paulo: Universidade de São Paulo, 1986.

Dois séculos e meio de história Xavante. In: CUNHA, M. C. da (Org.). História dos índios no Brasil. São Paulo: Companhia das Letras/Secretaria Municipal de Cultura/Fapesp, 1992.

MATO GROSSO (Estado). Ministério Público Federal. Procuradoria da República em Mato Grosso. Histórico da ação judicial para desintrusão da Terra Indígena Marãiwatsédé. Cuiabá: Procuradoria da República, 2014. Disponível em: 〈http://www.prmt.mpf.mp.br/documentos/histórico_mrw. pdf〉. Acesso em: 12 nov. 2015.

MAYBURY-LEWIS, D. A sociedade Xavante. Rio de Janeiro: Francisco Alves, 1984.

MELLO JORGE, M. H. P.; LAURENTI, R.; GOTLIEB, S. L. D. Avaliação dos Sistemas de Informação em Saúde no Brasil. Cadernos de Saúde Coletiva, Rio de Janeiro, v. 18, n. 1, p. 7-18, 2010.

PAGLIARO, H.; AZEVEDO, M. M.; SANTOS, R. V. (Org.). Demografia dos povos indígenas no Brasil. Rio de Janeiro: Editora Fiocruz/Associação Brasileira de Estudos Populacionais, 2005.

PEREIRA, N. O. M. Os indígenas nas informações censitárias: potencialidades e limitações com base em um estudo de caso sobre os Xavante, Mato Grosso. 2011. Tese (Doutorado) - Escola Nacional de Saúde Pública Sergio Arouca/Fiocruz, Rio de Janeiro, 2011.

PEREIRA, N. O. M.; SANTOS, R. V.; WELCH, J. R.; SOUZA, L. G.; COIMBRA JR., C. E. A. Demography, territory and identity of indigenous peoples in Brazil: the Xavante Indians and the 2000 Brazilian National Census. Human Organization, v. 68, n. 2, p. 166-180, 2009.

PISSOLATO, E. Mobilidade, multilocalidade, organização social e cosmologia: a experiência de grupos M'bya-Guarani no Sudeste brasileiro. Tellus, Campo Grande, ano 4, n. 6, p. 65-78, abr. 2004. 
RAVAGNANI, O. M. A experiência Xavante com o mundo dos brancos. Araraquara: Unesp, 1991.

SANTOS, R. V.; BASTOS, J. L.; CRUZ, O. G.; LONGO, L. A. F. B.; FLOWERS, N. M.; PEREIRA, N. O. $M$. Parity of indigenous and non-indigenous women in Brazil: does the reported number of children born depend upon who answers national census questions? Plos One, v. 10, n. 4, p. e0123826, 2015.

SIGNORINI, I. Língua(gem) e identidade: elementos para uma discussão no campo aplicado. Campinas: Mercado de Letras, 2002.

SOUSA, M. da C. de; SCATENA, J. H. G.; SANTOS, R. V. O Sistema de Informação da Atenção à Saúde Indígena (SIASI): criação, estrutura e funcionamento. Cadernos de Saúde Pública, Rio de Janeiro, v. 23, n. 4, p. 853-861, 2007.

SOUZA, L. G. Demografia e saúde dos índios Xavante do Brasil Central. 2008. Tese (Doutorado) - Escola Nacional de Saúde Pública Sergio Arouca/Fiocruz, Rio de Janeiro, 2008.

SOUZA, L. G.; SANTOS, R. V.; PAGLIARO, H.; CARVALHO, M. S.; FLOWERS, N. M.; COIMBRA JR., C. E. A. Demography and health of the Xavante Indians of Central. Cadernos de Saúde Pública, Rio de Janeiro, v. 27, n. 10, p. 1891-1905, 2011.

SOUZA, L. G.; SANTOS, R. V. Perfil demográfico da população indígena Xavánte de SangradouroVolta Grande, Mato Grosso (1993-1997), Brasil. Cadernos de Saúde Pública, Rio de Janeiro, v. 17, n. 2, p. 355-365, 2001.

Componente demográfico do sistema de informação da atenção à saúde indígena, Dsei-Xavante, Mato Grosso, Brasil. Cad. CRH, Salvador, v. 22, n. 57, p. 523-529, 2009.

STEPHENS, C.; PORTER, J.; NETTLETON, C.; WILLIS, R. Disappearing, displaced, and undervalued: a call to action for Indigenous health worldwide. Lancet, n. 367, p. 2019-2028, 2006.

TEIXEIRA, P. (Org.). Sateré-Mawê: retrato de um povo indígena. Manaus: Fundação Joaquim Nabuco, 2005.

UNESCO. Investir na diversidade cultural e no diálogo intercultural. Paris: Organização das Nações Unidas para a Educação, a Ciência e a Cultura, 2009 (Segundo Relatório Mundial da Unesco).

VASCONCELOS, A. N. M.; GOMES, M. M. F. Transição demográfica: a experiência brasileira. Epidemiologia e Serviços de Saúde, Brasília, v. 21, n. 4, dez. 2012. Disponível em: 〈http://scielo. iec.pa.gov.br/scielo.php?script=sci_arttext\&pid=S1679-9742012000400003\&lng=pt\&nrm=i so>. Acesso em: 24 nov. 2015.

WELCH, J. R. O sistema Xavante de grupos de idade espirituais: estrutura e prática na vida dos homens. In: COIMBRA JR., C. E. A.; WELCH, J. (Org.). Antropologia e história Xavante em perspectiva. Rio de Janeiro: Museu do Índio, Fundação Nacional do Índio, 2014. p.157-179.

\section{Sobre as autoras}

Luciene Guimarães de Souza é doutora em Saúde Pública pela Escola Nacional de Saúde Pública Sergio Arouca da Fundação Oswaldo Cruz - Ensp/Fiocruz e graduada em Ciências Sociais pela Universidade Federal de Juiz de Fora. Atualmente é vinculada à Secretaria Especial de Saúde Indígena - Sesai, atuando na Fundação Oswaldo Cruz/Escola Nacional de Saúde Pública Sergio Arouca.

Silvia Angela Gugelmin é doutora e mestre em Saúde Pública pela Escola Nacional de Saúde Pública Sergio Arouca, da Fundação Oswaldo Cruz - Ensp/Fiocruz e graduada em Nutrição pela 
Universidade Federal do Paraná. Professora adjunta II do Departamento de Saúde Coletiva, do Instituto de Saúde Coletiva - ISC da Universidade Federal de Mato Grosso.

Barbara Coelho Barbosa da Cunha é doutoranda e mestre em Epidemiologia em Saúde Pública pela Escola Nacional de Saúde Pública Sergio Arouca da Fundação Oswaldo Cruz - Ensp/ Fiocruz e graduada em Ciências Biológicas pela Universidade Estadual do Norte Fluminense Darcy Ribeiro - Uenf.

Marina Atanaka é doutora em Saúde Pública pela Fundação Oswaldo Cruz e em Saúde e Ambiente pela Universidade Federal de Mato Grosso e graduada em Enfermagem e Obstetrícia pela Escola de Enfermagem da Universidade de São Paulo. Professora da Universidade Federal de Mato Grosso

\section{Endereço para correspondência}

Luciene Guimarães de Souza

Av. Presidente Costa e Silva, 2025, Bairro São Pedro

36037-000 - Juiz de Fora-MG, Brasil

Silvia Angela Gugelmin

Av. Fernando Correa da Costa, 2367, Bloco CCBS III, Bairro Boa Esperança

78060-900 - Cuiabá-MT, Brasil

Barbara Coelho Barbosa da Cunha

Rua Carlos de Carvalho, 60/1407 Centro

20230-180 - Rio de Janeiro-RJ, Brasil

Marina Atanaka

Av. Fernando Correa da Costa, 2367, Bloco CCBS III, Bairro Boa Esperança 78060-900 - Cuiabá-MT, Brasil

\section{Abstract}

The Xavante indigenous people in the 2010 Population Census

The aim of this paper is to present, using the 2010 Census data, the geographical distribution and some sociodemographic characteristics of Xavante indigenous people in Brazil. The following variables of the basic questionnaire were considered: ethnicity; household residential situation; household location (inside or outside the Indigenous Land-IL); color or race; spoken language; income and literacy. The data were acquired from the Multidimensional Bank of Statistics (in Portuguese,,BME), a system to access aggregate data of the Brazilian Institute of Geography and Statistics, considering all Xavante IL,15 municipalities with IL Xavante, three municipalities surrounding the IL and Cuiabá city, capital of Mato Grosso state. Of the 19,259 declared Xavante, $92 \%$ lived in rural areas and $86 \%$ speak indigenous language at home. The municipalities Campinápolis, Barra do Garças, Nova Nazaré and General Carneiro, together added up, 75.1\% of the population living in rural areas. Within the IL Areões, Pimentel Barbosa and SangradouroVolta Grande all declared themselves indigenous and as Xavante ethnicity. In Chão Preto and Marechal Rondon only the question on whether the person "considered itself indigenous" managed to identiffy the Xavante, because all declared themselves in other categories of color or race in the race/color question. In comparison to other data source, the health information system, the results show that the total population captured in the 2010 Demographic Census was similar in both sources. The 2010 Demographic Census has a great potential for Xavante 
demographic data analysis and could be evaluated for other ethnicities, since compared to socio-anthropological information.

Keywords: Indigenous people. Demography. Population census. Xavante.

\section{Resumen}

Los indígenas Xavante en el Censo Demográfico de 2010

El objetivo de este artículo es presentar, utilizando los datos del Censo Demográfico de 2010, la distribución geográfica y las características demográficas de la etnia Xavante en Brasil. Con este fin, se investigaron las siguientes variables del cuestionario básico del censo: origen étnico; situación de residencia; ubicación del hogar (dentro o fuera de la Tierra Indígena-TI); color o raza; lengua hablada en el hogar; ingresos y alfabetización. Los datos fueron procesados con el Banco Estadístico Multidimensional (BME) del Instituto Brasileño de Geografía y Estadística, teniendo en cuenta los Xavante de las TI, los 15 municipios en que se encuentran las TI Xavante, los tres municipios que rodean las TI Xavante y la ciudad de Cuiabá, capital del estado de Mato Grosso. De los 19.259 indígenas declarados Xavante, el 91,6\% vivía en zonas rurales y el $85,9 \%$ hablaba un idioma indígena en el hogar. Los municipios de Campinápolis, Barra do Garças, Nova Nazaré, General Carneiro, juntos sumaron el 75,1\% de la población que vive en las zonas rurales. Dentro de las TI Areões, Pimentel Barbosa y Sangradouro Volta Grande, todos se declararon perteneciendo a la etnia indígena y Xavante. En Chão Preto y Marechal Rondon sólo con la pregunta "se considera indígena" se logró la identificación de ellos, porque todos se declararon en otras categorías en la pregunta de color o raza. En conclusión, los resultados muestran que los datos de población indígena Xavante total en el Censo Demográfico del 2010 son comparables con los encontrados en otra fuente, el sistema de información de salud, y presenta gran potencial para el análisis de datos demográficos de otros grupos indígenas específicos, cuando comparado a la información socioantropológica.

Palabras clave: Pueblos indígenas. Demografía. Censos de población. Xavante.

Recebido para publicação em 01/12/2015

Recomendado para publicação em 14/07/2016

Aceito para publicação em 09/10/2016 